\title{
0 cartaz "Os Elementos Químicos e a Vida" para ensino de Geociências na educação básica
}

The poster "The Chemical Elements and Life" for Geosciences teaching in basic education

\author{
Eduardo Profeta Ramos de Araujo ${ }^{1,4}$, Elias Araujo-Bressane ${ }^{2,4}$, Celso Dal Ré Carneiro 3,5 \\ 1 - Mestrando no Progr. Pós-Graduação em Ensino e História de Clências da Terra, Instituto de Geociências, Universidade Estadual de Campinas, Campinas, SP, Brasil. \\ 2 - Doutorando no Progr. Pós-Graduação em Ensino e História de Ciências da Terra, Instituto de Geociências, Universidade Estadual de Campinas, Campinas, SP, Brasil. \\ 3 - Docente, Progr. Pós-Graduação em Ensino e História de Ciências da Terra, Instituto de Geociências, Universidade Estadual de Campinas, Campinas, SP, Brasil. \\ 4 - BOLISTA CAPES \\ 5 - BOLISTA CNPQ.

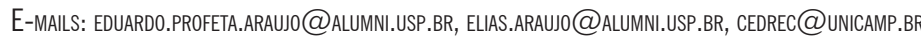

\begin{abstract}
This article presents results of a research project that promoted meaningful learning among students of basic education, while also offering the general public knowledge of Natural Sciences. The development of ludic and interactive activities allowed the integration of the subjects of Geography, Chemistry and Biology, especially for the first year of high school. By means of field research and production of illustrated posters, students reworked previously acquired knowledge, such as the water and rock cycles, rock weathering, soil formation, and information on chemical elements, minerals, rocks and distribution of natural resources. They also studied how such chemical elements are disaggregated and made available to living organisms. They created and produced posters and then posted them at food outlets, outside the school, for the benefit of the local community. Thus, the posters went beyond the school environment and reached the public, promoting a democratization of scientific knowledge.
\end{abstract}

Resumo: Este artigo apresenta os resultados de um projeto de pesquisa que buscou promover aprendizado significativo, junto a estudantes do ensino médio, e oferecer ao público não escolar conhecimentos sobre Ciências Naturais. As atividades lúdicas e interativas desenvolvidas possibilitaram a integração de conceitos das disciplinas Química, Geografia e Biologia, na medida em que os alunos retomaram conhecimentos sobre os ciclos da água e das rochas, 0 intemperismo de rochas e a formação de solos. Ao desenvolver pesquisas em campo e para fundamentar a produção de um cartaz ilustrado, exploraram informações sobre elementos químicos, minerais, rochas e distribuição de reservas naturais na crosta terrestre, além de pesquisar processos capazes de desagregar tais elementos químicos e disponibilizá-los no ambiente. Cópias do cartaz criado e produzido pelos alunos foram afixadas em locais de venda de alimentos, buscando democratizar o conhecimento científico junto ao público não escolar.
Citation/Citação: Araujo, E. P. R. de, Araujo-Bressane, E., \& Carneiro, C. D. R. (2020). 0 cartaz "Os Elementos Químicos e a Vida" para ensino de Geociências na educação básica. Terræ Didatica, 16, 1-10, e020027. doi: 10.20396/td.v16i0.8657238.

Keywords: Life. Biosciences. Geosciences. Geology. Food and health.

Palavras-chave: Vida. Biociências. Geociências. Geologia. Alimentação e saúde.

\section{Manuscript/Manuscrito:}

Received/Recebido: 25/10/2019

Revised/Corrigido: 10/02/2020

Accepted/Aceito: 16/06/2020

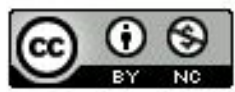

\section{Introdução}

A integração de disciplinas na área das Ciências da Natureza facilita a construção do conhecimento pelos alunos, principalmente quando se estabelecem novas relações entre currículos da educação básica. O esforço facilita a compreensão de processos naturais e permite o desenvolvimento de competências e habilidades relevantes.

A composição química das rochas, o ciclo da água, o intemperismo, a pedogênese e a constituição química dos organismos que compõem a biosfera são alguns temas discutidos na educação básica. No entanto, apesar de serem importantes para a compreensão do ciclo da vida, raramente são temas inter-relacionados, porque constam de disciplinas diferentes, particularmente em Química, Geografia e Biologia. Assim, muitas vezes, desperdiça-se a oportunidade de construir um significado concreto sobre tal conhecimento. A interdisciplinaridade e a transversalidade podem ser desenvolvidas para integrar as disciplinas, quando se oferecem aos alunos determinadas atividades lúdicas e interativas que despertem o interesse pela participação efetiva, conduzindo o estudante ao aprendizado significativo.

Este artigo focaliza especificamente a composição química dos alimentos, buscando situar as rochas e minerais encontrados no ambiente natural como fontes dos elementos para os seres vivos. Um dos resultados das atividades aqui descritas foi a 
composição do cartaz "Os elementos químicos e a vida", que ilustra as complexas relações existentes entre minerais, rochas, processos de intemperismo, formação de solos e desenvolvimento da biosfera. As atividades foram desenvolvidas junto a alunos e professores de ensino médio, compondo um recurso lúdico-didático que pode promover, de forma relevante, a consolidação do aprendizado, além de evitar a pura e simples memorização de conceitos.

A longa e demorada cadeia de processos naturais, geológicos e biológicos, pode ser moderadamente simplificada com fins didáticos, embora seja importante salientar que as rochas são simplesmente uma fonte remota dos elementos encontrados nos alimentos que consumimos. Assim, apesar de cada rocha possuir minerais cuja composição específica pode incluir determinado elemento de interesse, as rochas não são diretamente responsáveis pelo fornecimento das substâncias para os organismos vivos.

\section{Objetivos e justificativa}

O trabalho objetivou integrar assuntos curriculares tratados contemporaneamente nas disciplinas Química, Geografia e Biologia, no sentido de construir com os alunos uma série de conhecimentos sobre as principais fontes de elementos químicos indispensáveis para funções vitais do corpo humano. Enfatizou-se, nessa construção interativa de conhecimentos, a relação dos elementos químicos com a vida e a saúde humanas, bem como estudou-se a longa cadeia de interações que levam esses elementos até o organismo vivo, mediante alimentação equilibrada e saudável. O tema permite estabelecer um conjunto de instigantes relações entre composição química de determinados minerais e rochas, as condições naturais que possibilitam a desagregação dos minerais e rochas, a disponibilização de elementos químicos nos solos, ambientes aquáticos e atmosfera, e o aproveitamento desses elementos pelos seres vivos, incluindo os seres humanos, a fim de compor células, tecidos e órgãos que mantêm os sistemas dos organismos vivos em condições naturais de estruturação e metabolismo funcionais.

Os elementos coletados na pesquisa permitem vislumbrar que o trabalho é um projeto-piloto que integra experiências dos educadores e dos alunos, com potencial para se estender a outros saberes das demais áreas da educação básica.
Além da preocupação com a educação escolar, o trabalho buscou oferecer acesso ao conhecimento científico para o público não escolar, realizando divulgação dos trabalhos dos alunos, por meio de distribuição de cópias de um cartaz ilustrado (Fig. 1), afixadas em lanchonetes e restaurantes. Para concluir o projeto, estimulou-se os alunos a dissertar sobre a experiência obtida em função das atividades, incluindo relatos sobre a consolidação dos conhecimentos científicos e a relevância de se disponibilizar a educação escolar ao público externo à escola. Foi sugerido que os alunos apresentassem sugestões para agregar outros fatores no conjunto das atividades transversais e integrativas desenvolvidas.

\section{Materiais e métodos}

A proposta central envolve compreender os processos da educação escolar e estimular o aprendizado de temas transversais de Ciências da Natureza. A pesquisa foi desenvolvida com 120 alunos do ensino médio do Colégio Fereguetti, localizado no bairro Penha de França, do município de São Paulo, no ano de 2016. Buscou-se, inicialmente, estimular os alunos a se interessar pelo aprendizado, oferecendo-se, além de conteúdos programáticos do currículo escolar, atividades lúdicas e interativas que tornassem o aprendizado significativo e, assim, passível de ser consolidado.

\section{Integração dos professores e identificação de temas transversais}

Nos encontros pedagógicos curriculares entre educadores, surgiram questionamentos sobre a necessidade de oferecer aos alunos uma proposta de educação envolvendo disciplinas das Ciências da Natureza, a partir das Geociências, mas fundamentada na Química e na Biologia, sobre as transformações naturais do ambiente que influenciam a vida e a saúde humanas. O tema transversal proposto pelo professor responsável pela disciplina Geografia foi no sentido de conduzir os alunos a compreender que os elementos químicos que compõem o organismo humano estão envolvidos em ciclos naturais, quer contidos em minerais e rochas, quer como componentes da atmosfera, da hidrosfera e dos solos, quer como substâncias incorporadas aos organismos vivos, sendo responsáveis, portanto, pela constituição dos organismos e execução de suas funções celulares. 
Sob a coordenação do docente de Geografia, os professores das disciplinas envolvidas discutiram a integração dos temas, buscando promover, assim, a interdisciplinaridade. A finalidade foi compreender a importância do enfoque oferecido sobre o tema pela disciplina em pauta e definir etapas subsequentes de trabalho. Foram identificados os temas já trabalhados pelos professores em sala de aula, com o propósito de identificar interfaces curriculares e promover integração de assuntos que, até então, estiveram possivelmente dispersos ou fragmentados.

\section{Motivação dos alunos}

Foi necessário conhecer se os estudantes estariam realmente interessados em discutir o tema transversal "fontes dos elementos químicos que compõem o organismo humano e promovem o metabolismo celular". O questionamento aos alunos não foi direto. No decorrer das aulas de Geografia, o professor passou a identificar certa deficiência na correlação, estimulando-os a se interessar pelo assunto. As manifestações dos alunos foram imediatas e, a partir da evolução do interesse, acelerou-se a integração das disciplinas Geografia, Química e Biologia. A ação fundamental que motivou os alunos a participarem do projeto foi propor a eles que investigassem, em seus lares, os avisos inseridos nas embalagens de produtos industrializados, especialmente na parte de informações nutricionais e composições químicas dos alimentos. Foram também convidados a pesquisar as composições químicas de alimentos in natura, essenciais para o organismo humano.

Com as informações obtidas pelos alunos, houve colaboração dos professores de Química e Biologia, principalmente com relação ao ciclo natural dos elementos químicos e sua importância para a vida.

\section{Elaboração de cartaz}

As etapas de pesquisa teórica e de campo, cumpridas durante a investigação, evoluíram de acordo com a dinâmica dos trabalhos, envolvendo a coleta de novas fontes e materiais. As aulas prosseguiram, com a participação efetiva dos alunos, ao longo das etapas de planejamento, composição visual, diagramação e demais fases da elaboração e produção do cartaz de divulgação, apresentado na Figura 1 (Ver Material Suplementar).

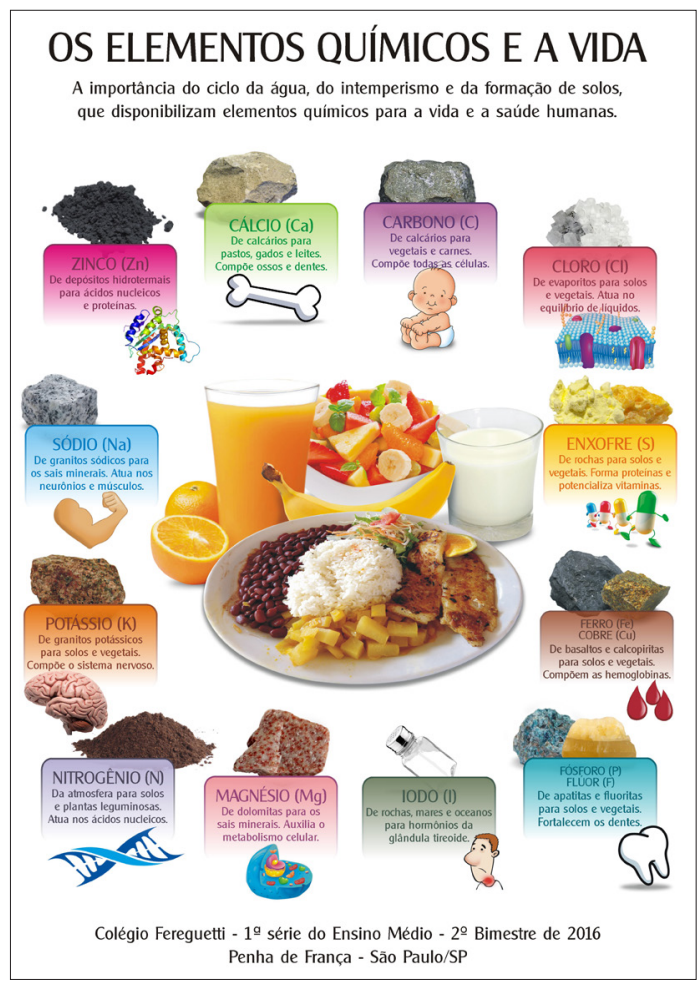

Figura 1. Cartaz "Os elementos químicos e a vida" (Ver Material Suplementar)

\section{Base conceitual: interdisciplinaridade e modelos de aprendizagem}

Para alcançar os objetivos iniciais, foi necessário investigar trabalhos anteriores sobre a abordagem pretendida. A revisão bibliográfica permitiu conhecer trabalhos de autores que tratam de educação em Ciências Naturais, especialmente nas áreas de Química, Geografia e Biologia.

\section{Elementos químicos e a vida}

A composição química do corpo humano, em sua estrutura e funções, e a origem das substâncias que participam dessa composição e do funcionamento do organismo constituem temas de interesse social, ou seja, trata-se de um tema transversal, cujo desenvolvimento é incentivado nas diversas disciplinas da educação básica (Carneiro et al., 2009, Lepsch, 2002, Valmiqui et al., 2007). Os grandes reservatórios de elementos químicos são os minerais, as rochas, os solos, a atmosfera e as águas continentais ou oceânicas (Teixeira et al., 2009, Wicander \& Monroe, 2011). A partir desses compartimentos naturais, os seres vivos obtêm os ingredientes para a composição e a manutenção dos organismos. A forma como as substâncias e os ele- 
mentos químicos são disponibilizados para os seres vivos depende de inúmeros fatores e processos das dinâmicas interna e externa do planeta.

Os processos da dinâmica interna da Terra constituem o motor da Tectônica de Placas, que afasta ou aproxima as grandes placas litosféricas, além de rebaixar ou soerguer grandes áreas, de modo a compor planícies ou planaltos (Teixeira et al., 2009, Wicander \& Monroe, 2011). A dinâmica externa do planeta, por sua vez, relaciona-se à energia solar. Ela movimenta o ciclo da água, que hidrata continuamente a superfície emersa do planeta e possibilita, mediante a participação de diferentes processos, o intemperismo das rochas superficiais (Toledo et al., 2014). Os processos pedogenéticos são também responsáveis pela disponibilização de substâncias e elementos químicos aos organismos autótrofos e heterótrofos, que se tornam importantes componentes estruturais ou funcionais das células dos organismos.

Assim, torna-se necessária a integração dos conhecimentos sobre os agentes da dissolução de substâncias minerais existentes nas rochas e a disponibilização de elementos químicos para compor a biomassa e suas reações celulares.

\section{A aprendizagem como processo}

A aprendizagem em Ciências da Natureza é um processo de desenvolvimento gradual que muitas vezes se afasta radicalmente da generalização, apesar do fato de que só se pode ensinar e aprender partindo do senso comum de que o aprendiz dispõe (Alves, 2007). Para ensinar um tema qualquer, o professor precisa possuir sensibilidade para compreender fatores primários dos alunos, envolvê-los nos temas desenvolvidos em sala de aula e propor uma progressão contínua de tarefas. Enfim, o ensino deve partir do conhecimento que as crianças e jovens possuem, transformando-o em conhecimento científico e reconstruindo sua realidade, sob nova contextualização de conhecimentos (Araujo, 2012). Freire (2003) afirma que ensinar não é necessariamente transmitir conhecimentos, mas criar a possibilidade para sua própria produção ou construção. O educador deve oferecer a seus alunos a possibilidade de fazer indagações e manifestações críticas, além de estimulá-los a participar do próprio processo de aprendizagem. Freire também assevera que não há como ensinar sem aprender. Não existe a possibilidade de segregar a docência do aprendizado do próprio professor. Apesar de haver papeis diferentes entre o professor e o aluno, um não reduz o objeto do outro. Não há docência sem discência (Freire, 2003): "quem ensina, aprende ao ensinar e quem aprende, ensina ao aprender" (Moreira, 2015).

Para Ausubel (1963), a aprendizagem significativa é um mecanismo humano, por excelência, para obter e armazenar a vasta quantidade de ideias e informações representadas em qualquer campo de conhecimento. A aprendizagem implica uma estreita relação entre o conteúdo a ser aprendido e aquilo que o aluno já sabe e se interessa em se aprofundar. A característica-chave da aprendizagem significativa é a "interação cognitiva entre novos conhecimentos e conhecimentos prévios especificamente relevantes", que já existem na estrutura cognitiva do aprendiz.

\section{Aprendizagem interativa}

A construção de recursos e mecanismos didáticos lúdicos e ilustrados pode beneficiar o aprendizado, na medida em que o lúdico oferece prazer, sentimento próprio do ser humano. A partir de atividades lúdicas, o aluno desenvolve várias capacidades, explorando e realizando uma reflexão sobre a realidade.

Segundo os Parâmetros Curriculares Nacionais (Brasil, 1998a), quando o estudo ocorre de forma exclusivamente livresca, sem interação direta com os fenômenos naturais ou tecnológicos, deixa enorme lacuna na formação dos estudantes. Por essa razão, além da confecção de um cartaz ilustrado, o projeto previu outras etapas que, em tempo oportuno, promovessem expansão das atividades entre os estudantes, dando sequência ao aprendizado sobre temas das Ciências Naturais. Um exemplo foi a criação e construção de um jogo da memória com enfoque similar.

\section{Multi, trans e interdisciplinaridade}

Moreira (2011) deduz que, em um modelo de ensino baseado em currículos e disciplinas, a multidisciplinaridade ocorre quando existe a possibilidade de serem obtidas informações ou construídos conhecimentos em disciplinas diferentes, sem, contudo, haver interligação entre as disciplinas.

Quanto à transdisciplinaridade, o autor afirma que o modelo descreve a cooperação entre as várias disciplinas, de tal forma que surge uma única disciplina. As abordagens deste trabalho não 
ocorrem para essa finalidade, ou seja, as disciplinas foram tratadas pelos professores responsáveis, mas com a preocupação de haver interação entre as abordagens ocorridas nas disciplinas distintas. Moreira (2011) define que a interdisciplinaridade, por sua vez, sobrevém quando há interação entre as disciplinas, sendo esse o princípio norteador deste trabalho. Foram integrados os diversos temas abordados em disciplinas distintas, com a finalidade de realizar a construção sólida de conhecimentos. Ao serem estabelecidas relações entre as disciplinas, é possível promover a interdisciplinaridade.

Para Menezes \& Santos (2001), há diferenças básicas entre a transversalidade e a interdisciplinaridade. Os autores afirmam que ambas rejeitam a concepção de conhecimento que tem a realidade como um conjunto de dados estáveis: a transversalidade se refere à dimensão didática, para a compreensão dos diferentes objetos de conhecimento, enquanto a interdisciplinaridade se refere à abordagem epistemológica dos objetos de conhecimento, porque questiona a visão compartimentada da realidade sobre a qual a educação se constitui.

\section{Parâmetros Curriculares Nacionais}

Foram analisados os Parâmetros Curriculares Nacionais (Brasil, 1998a, 1998b), das diversas áreas da educação básica, com a finalidade de identificar a importância do tema principal deste trabalho na aprendizagem, assim como ocorreram reuniões pedagógicas não sistemáticas, quando os docentes das disciplinas envolvidas, sob a coordenação do professor de Geografia, discutiram os temas integrados, interdisciplinarmente, para compreender sua importância e definir novas etapas.

Carneiro et al. (2004) defendem que o conhecimento em Geologia proporciona compreensão do funcionamento do planeta e, consequentemente, da Biosfera que o compõe, mas asseveram que os PCN, por si só, não são capazes de propor a interação dos currículos escolares. Os autores defendem o enriquecimento curricular da educação básica, mediante a introdução das Geociências como integradora das demais Ciências da Natureza, incluindo muitos aspectos geológicos, sem a fragmentação de conhecimentos até então não abolida pelos PCN.

Quando o projeto foi desenvolvido, a Base Nacional Comum Curricular, prevista na Lei de Diretrizes e Bases da Educação, ainda se encontrava na fase de elaboração.

\section{Resultados}

O trabalho levou à obtenção de resultados especialmente qualitativos, ou seja, não se buscou obter resultados quantitativos, envolvendo revisão de conceitos e realização de entrevistas e consultas, o que trouxe liberdade à exposição dos resultados. Nesta seção, serão apresentados os objetos de estudo e os resultados finais obtidos. Como se trata de trabalho experimental e ainda em evolução, que busca integrar disciplinas em temas transversais para valorizar a aprendizagem significativa, objetiva-se também, posteriormente, envolver outras séries ou anos da educação básica da escola componente da pesquisa, em outros assuntos curriculares.

\section{Duas ressalvas}

Para abordar temas que relacionam os elementos químicos existentes na natureza com sua transformação progressiva em substâncias químicas necessárias ao organismo humano, parece adequado integrar o conhecimento sobre composição química de determinados minerais e rochas com outros processos naturais, notadamente as ações da natureza que promovem dissolução e mobilização das substâncias e posteriormente disponibilizam os elementos químicos em ambientes naturais. Estes, por sua vez, são aproveitados pelos seres vivos para deles extrair substâncias que compõem sua biomassa e realizam as reações e funções celulares.

Em contrapartida, uma vez que as rochas são formadas por um ou mais minerais e cada mineral possui composição química definida, quando se pulverizam tais substâncias para obter um pó de rocha, o material resultante pode ser utilizado como fertilizante na agricultura. A técnica, denominada rochagem, reduz o impacto agrícola no ambiente, ao evitar o empobrecimento do solo; no caso de calcários dolomíticos, o processo denominado calagem corrige condições de excessiva acidez de solos. Tanto a rochagem como a calagem melhoram a produção dos alimentos, ao introduzir mudanças significativas das condições do solo e ao disponibilizar substâncias úteis para as plantas. Os conceitos de calagem e rochagem são relevantes: conforme assinalado acima, as rochas não fornecem, diretamente, elementos químicos aos alimentos, apesar de, eventualmente, sua composição específica incluir os elementos citados no cartaz ora descrito. Deslocar o olhar de professores e alunos para o complexo caminho percorrido pelos elementos 
químicos, desde as rochas e seus minerais, formados há milhões de anos, até a comida que é colocada no prato de cada um, pode motivar os estudantes a examinar com mais atenção os processos naturais e a relação do Homem com a Natureza.

\section{0 cartaz ilustrado}

O cartaz foi estruturado em folha sulfite da cor branca, tamanho A3 (29,7 x 42,0 centímetros), na orientação denominada retrato. Optou-se pela gramatura de $90 \mathrm{~g} / \mathrm{m}^{2}$, porque oferece melhor resistência ao manuseio e afixação em paredes ou balcões de ambientes públicos. Para ilustrar o cartaz, foram citados os mesmos minerais, rochas e outras substâncias naturais utilizados durante as aulas teóricas, relacionando-os aos elementos químicos que participam de suas composições e que são aproveitados pelo organismo humano. Outros fatores que conduziram à escolha dessas substâncias referem-se à ocorrência na região e facilidade de serem obtidos na natureza, em depósitos de materiais de construção e lojas especializadas em produtos químicos ou que comercializam amostras destinadas a colecionadores e afins.

O título do cartaz possui o seguinte cabeçalho: Os elementos químicos e a vida, com o seguinte subtítulo: A importância do ciclo da água, do intemperismo e da formação de solos, que disponibilizam elementos químicos para a vida e a saúde humanas. No rodapé do cartaz, foi inserida a identificação do Colégio Fereguetti. No centro, foram inseridos um prato básico de refeição, frutas, um copo contendo suco de laranja e outro contendo leite. Ao redor dos alimentos, constam imagens de alguns minerais, rochas e compostos naturais, relacionados a determinadas funções do organismo humano e ilustrados com os seguintes resumos:

- Zinco $(\mathrm{Zn})$ : oriundo de depósitos hidrotermais para ácidos nucleicos e proteínas.

- Cálcio $(\mathrm{Ca})$ : oriundo de calcários para pastos, gados e leites. Compõe ossos e dentes.

- Carbono (C): oriundo de calcários para vegetais e carnes. Compõe todas as células.

- Cloro (Cl): oriundo de evaporitos para solos e vegetais. Atua no equilíbrio de líquidos.

- Enxofre (S): oriundo de rochas para solos e vegetais. Forma proteínas e potencializa vitaminas.

- Ferro $(\mathrm{Fe})$ e Cobre $(\mathrm{Cu})$ : oriundos de basaltos e calcopiritas para solos e vegetais. Compõem as hemoglobinas.
- Fósforo (P) e Flúor (F): oriundos de apatitas e fluoritas para solos e vegetais. Fortalecem os dentes.

- Iodo (I): oriundo de rochas, mares e oceanos para hormônios da glândula tireoide.

- Magnésio $(\mathrm{Mg})$ : oriundo de dolomitas para os sais minerais. Auxilia o metabolismo celular.

- Nitrogênio $(\mathrm{N})$ : oriundo da atmosfera para solos e plantas leguminosas. Atua nos ácidos nucleicos.

- Potássio (K): oriundo de granitos potássicos para solos e vegetais. Compõe o sistema nervoso.

- Sódio ( $\mathrm{Na}$ ): oriundo de granitos sódicos para os sais minerais. Atua nos neurônios e músculos.

Foram impressas e distribuídas aos alunos cerca de 80 cópias do cartaz, para divulgá-lo junto aos familiares e em estabelecimentos comerciais localizados das proximidades. Todas as etapas das atividades práticas foram realizadas mediante orientação direta dos professores e consentimento expresso dos pais ou responsáveis pelos alunos.

\section{Divulgação ao público não escolar}

Inicialmente, como experiência piloto ou fase de treinamento, os alunos realizaram contato e descreveram o projeto ao responsável pela lanchonete existente dentro da própria escola onde a pesquisa foi realizada. Posteriormente, cópias do cartaz foram utilizadas para divulgação ao público não escolar, em ambientes externos. Sempre supervisionados pelo professor de Geografia, os próprios alunos realizavam contatos com os comerciantes do entorno da escola, como mercados ou empórios, panificadoras, lanchonetes e restaurantes, descreviam as propostas do projeto e afixavam cópias do cartaz em locais de fácil acesso ou visualização pelo público (Fig. 2).

A divulgação externa ocorreu ao longo de uma semana, em horário extracurricular, sendo possível percorrer 18 estabelecimentos comerciais. Não houve rejeição ou manifestações contrárias pelos comerciantes. Na realidade, a aceitação surpreendeu os alunos, não acostumados com tanta facilidade. Valorizaram-se comportamentos que levam à alimentação saudável e a práticas sociais indispensáveis, ao se observar a interação dos alunos com o público externo. Promove-se, dessa forma, alguns dos papeis primordiais da escola, como a construção de conhecimentos por meio da forma- 


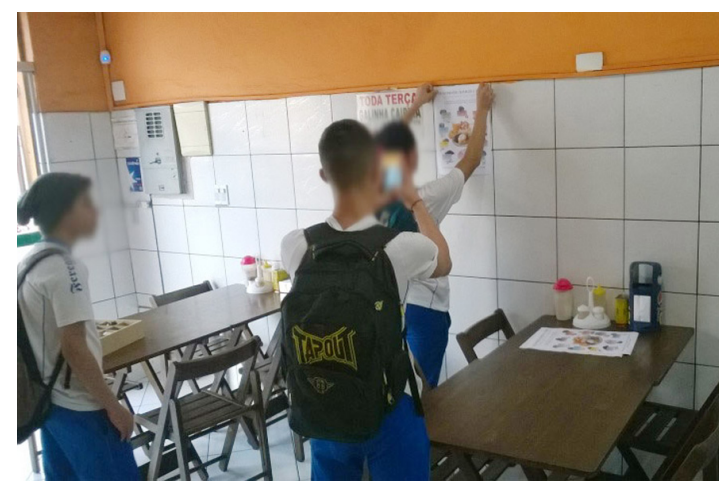

Figura 2. Imagens da divulgação do cartaz "Os elementos químicos e a vida" em estabelecimento comercial

ção cidadã e plena de seus estudantes e a difusão de conhecimentos científicos ao público não escolar.

\section{Percepções e avaliação dos resultados}

As avaliações foram realizadas durante todas as fases do trabalho, com a finalidade de mensurar resultados e propor redefinições de ações didático-pedagógicas, principalmente em razão de se tratar de um projeto-piloto. Como já abordado, não houve pretensão de realizar avaliações quantitativas, por se tratar de projeto-piloto exploratório. Foi possível observar pleno interesse dos educadores e da direção escolar. Os professores envolvidos se mobilizaram para apresentar e articular as fases curriculares necessárias para integrar os assuntos ou temas em desenvolvimento. Os recursos didáticos necessários ao projeto foram disponibilizados pela direção escolar, como também as comunicações aos responsáveis pelos alunos envolvidos nas atividades, em razão de haver práticas também em lugares externos, ou seja, fora do ambiente escolar.

A avaliação qualitativa dos resultados foi essencial para corrigir rumos e inserir novos fatores, que podem ser replicados em outras séries escolares. As ideias apresentadas, embora ainda preliminares e passíveis de aprimoramento, influenciaram a prática pedagógica dos participantes.

As ações do professor da escola tradicional, que atua como mero transmissor de informações, em aulas nas quais predomina o discurso monólogo, foram substituídas por ações que valorizaram a interatividade e integração dos alunos, enriquecendo o aprendizado. A proposta valorizou o papel do professor como proponente de ideias e orientador de ações. A integração dos temas das diferentes disciplinas foi alcançada, principalmente graças à comunicação efetiva entre os professores, para preparar as aulas e oferecer aos alunos temas inter-relacionados e enriquecedores.

A participação dos alunos obteve resultados positivos, bem acima do esperado. Assim que foram informados sobre o projeto, revelaram interesse e motivação. Praticamente todos se envolveram em discussões sobre a possibilidade de desenvolver temas transversais e reconheceram a necessidade de integrar as disciplinas. A receptividade aos métodos que seriam utilizados foi recompensada pela total liberdade para que propusessem ações cuja importância fosse reconhecida.

Dentre as propostas apresentadas pelos estudantes, destacaram-se a possibilidade de iniciar a divulgação dos cartazes a partir do ambiente escolar, ou seja, na própria lanchonete do colégio, para que houvesse percepção da aceitação pelo público, e de realizar as ações externas em estabelecimentos comerciais do entorno da escola, para proprietários ou responsáveis conhecidos por eles, a fim de evitar rejeições e, assim, evitar frustração.

Foram observadas e avaliadas as condutas dos alunos, com necessárias ações dos educadores para evitar indisciplinas, atendendo às regras do próprio colégio, que adota, como fator de avaliação escolar, atribuição de conceitos em razão de condutas sociais. Por essa razão, todos foram cientificados quanto ao necessário respeito mútuo e quanto às decisões dos comerciantes e demais integrantes do público não escolar, durante a realização das atividades externas.

A evidente diferença de comportamento entre os alunos era esperada. Notou-se que alguns são introspectivos ou reservados, outros são proativos e alguns hiperativos. As diferentes formas de se expressar não geraram condutas ou eventos relevantes ou desagradáveis que pudessem interferir no desempenho das aulas, quer no ambiente escolar, quer no ambiente externo.

O trabalho também foi avaliado quanto à receptividade do público externo. Despertou interesse e motivou pessoas componentes do meio não escolar. Os comerciantes compreenderam a importância das atividades, autorizaram a afixação de cópias do cartaz, sendo que alguns até expressaram interesse destacado e satisfação que motivaram os alunos. Ao final, os alunos relataram individualmente a experiência em dissertação escrita, expondo os conhecimentos curriculares que agregaram e as percepções que construíram em razão da integração de temas de disciplinas diferentes, do uso de recursos didáticos interativos e lúdicos e da atividade exter-

\begin{tabular}{c|c|c|c|c|c|}
\hline (C) Terrae Didat. & Campinas, SP & v.16 & $1-8$ & $\mathrm{e} 020027$ & 2020 \\
\hline
\end{tabular}


na realizada. Os relatórios não foram utilizados na avaliação do aprendizado dos alunos, mas podem ser aproveitados no aperfeiçoamento de atividades semelhantes no futuro.

\section{Conclusões}

Considerado um projeto-piloto, este trabalho foi desenvolvido a partir de temas transversais da Educação, mediante o envolvimento efetivo da direção escolar, de professores e de alunos da $1^{\text {a }}$ série do ensino médio em uma escola particular, situada no bairro Penha de França, zona leste da Capital de São Paulo. Além de mostrar aos alunos o relevante papel democrático da escola, os objetivos principais foram a integração de disciplinas e alguns dos seus temas curriculares, o estímulo à motivação para que os alunos participassem das atividades teóricas e práticas e elevassem sua capacidade cognitiva para compreender aspectos relacionados ao ciclo natural de elementos químicos essenciais à vida e saúde humanas.

As atividades promoveram o enriquecimento do aprendizado sobre: (a) composição química de determinados minerais, rochas, solos e outros recursos naturais; (b) importância dos agentes que interferem no ciclo da água, no intemperismo, na desagregação e mobilização de elementos e substâncias químicas, na formação de solos e dos ambientes nos quais os organismos obtêm alimentos e nutrientes importantes para a plena manutenção da vida.

Com o apoio logístico oferecido pelo colégio, harmonizaram-se ações dos professores das diferentes disciplinas enquanto os alunos foram estimulados a interagir, valorizando-se diversas concepções tipicamente educacionais: pertencimento, ações colaborativas, utilização de recursos educativos lúdicos, transversalidade no ensino, aprendizagem integrativa entre docente e discente, e percepções sobre a importância da aprendizagem significativa.

\section{Agradecimentos}

Os autores agradecem à Coordenação de Aperfeiçoamento de Pessoal de Nível Superior (CAPES) pela concessão de bolsas de Programa de Demanda Social a dois autores (EPRA e EAB) e ao Conselho Nacional de Desenvolvimento Científico e Tecnológico (CNPq) pela concessão de bolsa de Produtividade em Pesquisa a um autor (CDRC).

\section{Referências}

Alves, R. (2007). Filosofia da ciência. Introdução ao jogo e suas regras. 12 ed. São Paulo: Loyola.

Araujo, E. P. R. (2012). Ciências da Terra em cursos superiores de ciências biológicas que habilitam ao magistério de Ciências Naturais para o ensino fundamental. Dissertação (Mestrado). Campinas, SP: Instituto de Geociências, Universidade Estadual de Campinas. URL: http://repositorio.unicamp.br/jspui/handle/REPOSIP/287011. Acesso 12.06.2020.

Ausubel, D. (1963). The psychology of meaningful verbal learning. New York: Grune and Stratton.

Brasil. Ministério da Educação, Secretaria de Educação Média e Tecnológica. (1998a). Parâmetros Curriculares Nacionais: Ciências Naturais. Brasília, DF: MEC/SEF. URL: https://www.cpt.com.br/pcn/parametros-curricularesnacionais-ciencias-naturais. Acesso 13.06.2020.

Brasil. Ministério da Educação, Secretaria de Educação Média e Tecnológica. (1998b). Parâmetros Curriculares Nacionais: terceiro e quarto ciclos. Temas transversais. Brasília, DF: MEC/SEF. URL: portal.mec.gov.br/seb/ arquivos/pdf/ttransversais.pdf. Acesso 13.06.2020.

Carneiro, C. D. R., Toledo, M. C. M. de, Almeida, F. F. M. de. (2004). Dez motivos para a inclusão de temas de Geologia na Educação Básica. Revista Brasileira de Geociências, 34(4), 553-560. doi: 10.25249/03757536.2004344553560 .

Carneiro, C. D. R., Gonçalves, P. W., \& Lopes, O. R. (2009). O ciclo das rochas na natureza. Terra Didatica, 5(1), 50-62. doi: 10.20396/td.v5i1.8637502.

Freire, P. (2003). Pedagogia da autonomia: saberes necessários à prática educativa. 27 ed. São Paulo: Paz e Terra.

Lepsch, I. F. (2002). Formação e conservação de solos. São Paulo: Oficina de Textos.

Menezes, E. T., \& Santos, T. H. (2001). Verbete transversalidade. Dicionário Interativo da Educação Brasileira. Educabrasil. São Paulo: Midiamix.

Moreira, M. A. (2011). Teorias de aprendizagem. 2 ed. São Paulo: EPU.

Moreira, M. A. (2015). Aprendizagem significativa. Campos conceituais e Pedagogia da Autonomia: implicações para o ensino. In: versão artigo de conferências plenárias da XVII Reuniõn de Enseñanza de la Física, Córdoba, Argentina, set 2011 e Educon, Aracaju, SE, Brasil, set 2015. (Publ. em Espanhol por Aprendizagem Significativa em Revista, 2(1), 44-65). URL: http://educonse.com.br/ixcoloquio/Artigo_Aprendizagem. pdf. Acesso 13.06.2020.

Teixeira, W., Fairchild, T., Toledo, M. C. M. de, \& Taioli, F. (2009). Decifrando a Terra. 2 ed. São Paulo: IBEP/ Ed. Nacional-Conrad.

Toledo, M. C. M. de, Teixeira, W., \& Bourotte, C. L. M. (2014). Geologia. São Paulo: Edusp.

Valmiqui, C. L., Lima, M. R., \& Melo, V. F. (2007). O solo no meio ambiente: abordagem para professores do ensino fundamental e médio e alunos do ensino médio. Curitiba: Ed. UFPR.

Wicander, R., \& Monroe, J. S. (2011). Fundamentos de Geologia. São Paulo: Cengage Learning. 